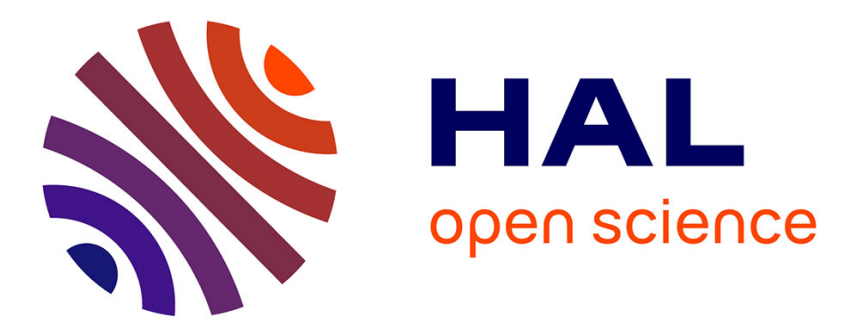

\title{
Dietary antioxidants: Do they have a role to play in the ongoing fight against abnormal glucose metabolism?
}

\author{
Antoine Avignon, Marie Hokayem, Catherine Bisbal, Karen Lambert
}

\section{To cite this version:}

Antoine Avignon, Marie Hokayem, Catherine Bisbal, Karen Lambert. Dietary antioxidants: Do they have a role to play in the ongoing fight against abnormal glucose metabolism?. Nutrition, 2012, 10.1016/j.nut.2012.01.001 . hal-02537052

\section{HAL Id: hal-02537052 \\ https://hal.umontpellier.fr/hal-02537052}

Submitted on 8 Apr 2020

HAL is a multi-disciplinary open access archive for the deposit and dissemination of scientific research documents, whether they are published or not. The documents may come from teaching and research institutions in France or abroad, or from public or private research centers.
L'archive ouverte pluridisciplinaire HAL, est destinée au dépôt et à la diffusion de documents scientifiques de niveau recherche, publiés ou non, émanant des établissements d'enseignement et de recherche français ou étrangers, des laboratoires publics ou privés. 


\title{
Review
}

\section{Dietary antioxidants: Do they have a role to play in the ongoing fight against abnormal glucose metabolism?}

\author{
Antoine Avignon M.D., Ph.D. ${ }^{\text {a,b,c,*, Marie Hokayem Ph.D. Student }}{ }^{\text {a,b }}$, Catherine Bisbal Ph.D. ${ }^{\text {a,b }}$, \\ Karen Lambert Ph.D. ${ }^{\text {a,b }}$ \\ a INSERM U1046, Physiologie E Médecine Expérimentale du Cœur et des Muscles, Montpellier, France \\ ${ }^{\mathrm{b}}$ Université Montpellier I, Université Montpellier II, Montpellier, France \\ ${ }^{\mathrm{c}} \mathrm{CHU}$ Montpellier, Montpellier, France
}

Keywords:

Oxidative stress

Glucose metabolism

Insulin resistance

Antioxidants

\begin{abstract}
A B S T R A C T
Overfeeding, an increased intake of saturated fatty acids, and sugary foods are key dietary changes that have occurred in recent decades in addition to the emergence of the obesity epidemic. In addition to an increase in energy storage as fat, these dietary changes are accompanied by an increase in mitochondrial macronutrient oxidation, leading to an excessive free radical production and, hence, oxidative stress. The latter has long been considered a central mechanism linking nutrient overload, insulin resistance, the metabolic syndrome, and diabetes. However, food, through fruit and vegetable consumption, also can be a great source of antioxidants that protect the body against oxidative damage and insulin resistance and thus help cope with the metabolic backlash of the energy-dense Westernized diet. Experimental data are in favor of the beneficial role conveyed by antioxidants in glucose metabolism, but clinical data in humans remain controversial. This review therefore aimed to sort out any underlying discrepancies and provide an overall clear view of the role of antioxidants in the ongoing fight against abnormal glucose metabolism.
\end{abstract}

\section{Introduction}

The obesogenic dietary changes of recent decades, the key aspects of which are increased fatty and sugary food intake in parallel to a decrease in fruit and vegetable consumption, have been proposed to play essential roles in the growing epidemic of chronic diseases afflicting developed and developing countries. These dietary changes combined with a sedentary lifestyle force the body to manage excess energy that must be metabolized. One of the expected actions is increased energy storage as fat, and other macronutrients undergo oxidation in the mitochondria, favoring an increased production of free radicals and oxidative stress, which has long been proposed as a unifying mechanism linking excessive nutrient intake, insulin resistance (IR), the metabolic syndrome, and diabetes. Beyond the quantitative aspects of food ingestion, quality is just as important in the development of oxidative stress; for example, different types of fatty acids have variable effects on the production of free radicals. Moreover, nutrition is a potent tool in regulating

\footnotetext{
This work was supported by the French National Research Agency.

* Corresponding author. Tel.: +33-467-338-406; fax: +33-467-339-591.

E-mail address: a-avignon@chu-montpellier.fr (A. Avignon).
}

glucose metabolism, and it has been reported that food rich in antioxidants such as food in the Mediterranean diet might be protective [1,2].

We recently summarized the data linking oxidative stress to diet and to IR and the preventive role of antioxidants against these metabolic alterations [3]. In the present review, we present an update of recent discoveries in this rapidly evolving field, try to sort out any underlying controversies, and supply a global recapitulative view of the role of antioxidants in the ongoing fight against an abnormal glucose metabolism.

\section{Oxidative stress and insulin resistance}

Reactive oxygen species (ROS), or free radicals, are atoms or molecules characterized by an unpaired electron that allows the atoms or molecules to react with various molecules present at their site of formation (Table 1 ). They are produced within the cell by different mechanisms; the main source of superoxide anions is mitochondrial by the electron transport chain. Other precursors of endogenous superoxides include reduced nicotinamide adenine dinucleotide phosphate oxidase, xanthine oxidase, nitrite oxide synthase, the endoplasmic reticulum, an unfolded 
Table 1

Major reactive species: origins and antioxidant defenses

\begin{tabular}{|c|c|c|}
\hline $\begin{array}{l}\text { Reactive } \\
\text { species }\end{array}$ & $\begin{array}{l}\text { Cellular sources of } \\
\text { reactive species }\end{array}$ & $\begin{array}{l}\text { Antioxidative } \\
\text { systems }\end{array}$ \\
\hline $\mathrm{O}_{2}^{-}$ & $\begin{array}{l}\text { mitochondria: ETC; membrane } \\
\text { and cytoplasm: NOX; } \\
\text { endoplasmic reticulum: } \\
\text { oxidative protein folding (PDI1 } \\
\text { and ERO); peroxisome: } \\
\beta \text {-oxidation of fatty acids; } \\
\text { cytosolic oxidase (xanthine } \\
\text { oxidase, lipoxygenase, } \\
\text { cyclooxygenase) }\end{array}$ & $\begin{array}{l}\text { Mn-SOD, CuZn-SOD, } \\
\text { CuZn-SOD }\end{array}$ \\
\hline \multirow[t]{3}{*}{$\mathrm{H}_{2} \mathrm{O}_{2}$} & $\begin{array}{l}\text { from } \mathrm{O}_{2}^{-} \text {in cytoplasm by } \\
\text { CuZn-SOD }\end{array}$ & catalase \\
\hline & $\begin{array}{l}\text { from } \mathrm{O}_{2}{ }^{-} \text {in mitochondria by } \\
\mathrm{Mn}-\mathrm{SOD}\end{array}$ & GPx \\
\hline & monoamine oxidase & $\operatorname{Trx} / \operatorname{Prdx}$ \\
\hline $\mathrm{OH}$ & $\begin{array}{l}\text { from } \mathrm{H}_{2} \mathrm{O}_{2} \text { in cytoplasm by } \\
\mathrm{Cu}^{2+}, \mathrm{Fe}^{2+} \text { (Fenton reaction) }\end{array}$ & $\mathrm{H}_{2} \mathrm{O}$ spontaneous reaction \\
\hline \multicolumn{3}{|c|}{ 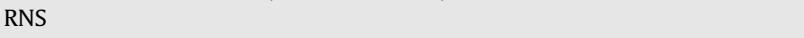 } \\
\hline NO & NOS & \\
\hline ONOO- & from $\mathrm{NO}$ with $\mathrm{O}_{2}^{-}$ & hydroxyl/carboxyl radicals \\
\hline
\end{tabular}

CuZn-SOD, cytosolic superoxide dismutase; ERO, endoplasmic reticulum oxidoreductase; ETC, electron transport chain; GPx, glutathione peroxidase; $\mathrm{H}_{2} \mathrm{O}_{2}$, hydrogen peroxide; Mn-SOD, mitochondrial superoxide dismutase; NO, nitric oxide; NOS, nitric oxide synthase; NOX, reduced nicotinamide adenine dinucleotide phosphate oxidase; $\mathrm{O}_{2}{ }^{-}$, superoxide anion; $\mathrm{OH}$, hydroxyl radical; ONOO-, peroxynitrite; PDI1, protein disulfide isomerase-1; Prdx, peroxiredoxin; RNS, reactive nitrogen species; Trx, thioredoxin

protein response, and the lipid membrane, particularly arachidonic acid degradation. Oxidants are naturally neutralized or detoxified by antioxidant enzymes such as superoxide dismutase, catalase, and glutathione peroxidase and by non-enzymatic antioxidants including glutathione, uric acid, reduced nicotinamide adenine dinucleotide phosphate, coenzyme $\mathrm{Q}$ albumin, and bilirubin. This endogenous antioxidant system is supplemented by exogenous originating reducing compounds encompassing vitamin C, vitamin E, carotenoids, and polyphenols that play essential roles in many antioxidant mechanisms. When in excess, ROS interact with macromolecules and may lead to molecular alterations such as DNA fragmentation, lipid peroxidation, or protein carbonylation. However, ROS are also essential for many biological processes, including insulin-signaling transduction (Fig. 1) [3]; thus, they must not be seen as only toxic compounds. Then, "oxidative stress" results from an imbalance between the generation of ROS and the defense mechanisms against ROS (pro-oxidant-antioxidant imbalance). However, this remains an oversimplistic view of a highly complex process, with recent evidence suggesting that redox is considerably compartmentalized inside the cell. To this extent, the redox potential varies between subcellular compartments by differentially regulating redox-sensitive processes in distinctive parts of the cell, resulting in redox circuits that are kinetically limited and insulated from each other. For this reason, oxidative stress has been proposed to result from a disruption of these circuits (reviewed by Jones and Go [4]). Whatever its origin, oxidative stress leads to a toxic environment in which macromolecules are oxidatively damaged and cellular functions are altered.

Conversely, IR is defined as a decrease in insulin action, be it the cellular capture of glucose by muscle and fat cells or the inhibition of hepatic glucose production. It is found in numerous medical conditions, the most common being obesity, diabetes, and the metabolic syndrome, but also essential hypertension, polycystic ovary syndrome, hepatitis $\mathrm{C}$, antiretroviral therapy for human immunodeficiency viral infection, and even Helicobacter pylori infection, among others. In addition to an insulin secretion defect, it represents one of the two core pathophysiologic mechanisms of type 2 diabetes (T2D). The determinants of IR are genetic and environmental, with the latter playing an important role in the development of IR dependent on a specific genetic background. In fact, the insulin-signaling cascade constitutes a complex signaling network; each step is interconnected with another. That is why the abrogation of one pathway can be compensated by another, allowing the ongoing propagation of the signal. Thus, understanding the mechanisms involved in IR is fairly difficult and thus far only fractional. The assumption that oxidative stress can be a mandatory mechanistic common denominator linking the many forms of IR has received increasing attention in recent years [5]. Indeed, be they in vitro or in vivo, the varied circumstances of IR are associated with oxidative stress and the diverse pharmacologic and transgenic approaches decreasing ROS levels, all improve insulin sensitivity to varying degrees [6]. More precisely, ROS production by the mitochondria and mitochondrial oxidative stress seem to be involved in IR [6]. These studies therefore suggest that mitochondrial superoxide production may be a unifying mechanism of IR and could well be the missing link between overeating and IR, as previously observed [7].

\section{Diet and oxidative stress}

In a recent review, we reported evidence showing that oxidative stress is a core mechanism connecting overfeeding to IR [3]. Briefly, in humans, obesity and more specifically visceral fat are associated with oxidative stress, which is reversed by weight loss. Multiple processes have been reported to be involved in obesity-associated oxidative stress, including a high metabolic load that exposes cells to an overload of nutrients with excessive mitochondrial oxidation and increased ROS generation, inflammation, endoplasmic reticulum stress, and endocrine dysregulations, mainly hyperinsulinemia. Beyond weight gain, the metabolic load per se is recognized as a decisive element of oxidative stress, because high-fat, high-carbohydrate meals increase oxidative stress and inflammation measured in peripheral blood cells [8] and in the skeletal muscles of lean volunteers [9]. Indeed, markers of oxidative stress are altered after eating a single high-fat, high-carbohydrate meal [9], specifically during the postprandial period, which is particularly sensitive in light of how postprandial hyperlipidemia, hyperglycemia, and hyperinsulinemia are associated with increased oxidative stress [10]. Supporting the importance of the postprandial period, in patients with T2D it has been shown that exenatide, a glucagon-like peptide-1 analog with marked effects on the postprandial metabolic control of blood glucose and lipid levels, induces favorable changes in oxidative stress markers after $1 \mathrm{y}$ of treatment compared with insulin glargine, which is mainly effective on fasting plasma glucose [11]. Susceptibility to metabolic load varies from one individual to another, but people with IR, obesity, or a family history of T2D are particularly vulnerable [12,13]. In regard to the significance of the postprandial period, one can easily imagine the consequences of a Westernized diet with its daily repeated snacking of energy-dense foods.

Any energy overload ensured by carbohydrates or lipids or even proteins leads to an increased ROS production and eventually oxidative stress [8]. However, the quality of macronutrients plays a decisive part, particularly when considering the nature of the fatty acids consumed. Experimental data have consistently shown that lipid toxicity is caused primarily by saturated fatty acids and involves oxidative stress, an effect that 


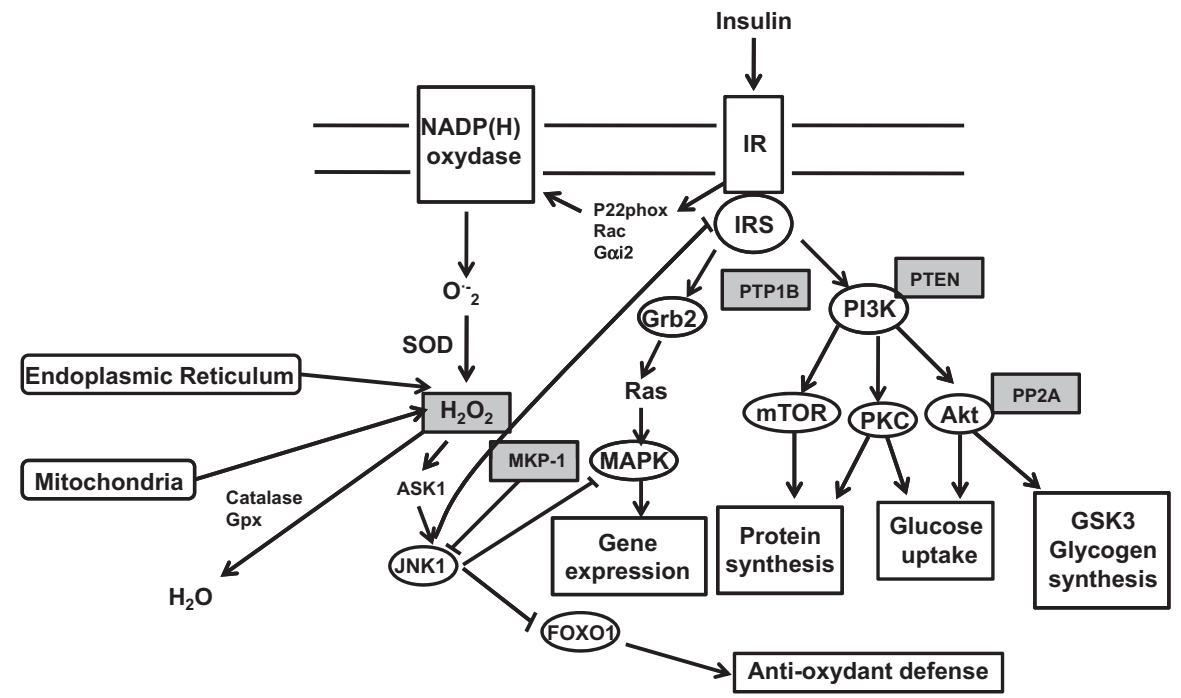

Fig. 1. Scheme of insulin signaling cascade and its regulation by $\mathrm{H}_{2} \mathrm{O}_{2}$. Insulin binding to its receptor, a ligand-activated tyrosine kinase, catalyzes the tyrosine autophosphorylation of the IR and of its cellular IRS. The insulin signal is then transmitted to the different proteins associated with the phospho-tyrosyl side chains of the IRS by their src homology 2 domain. PI3K is linked to the activation of glucose transport, protein synthesis, and gene expression; Grb2 by the Ras pathway is linked to the regulation of gene expression. The steady-state level of tyrosine phosphorylation is regulated by PTPases (e.g., PTP1B), which are directly sensitive to the cysteine oxidation leading to their inhibition. Moreover, other important regulators of this pathway (PTEN, PP2A, MKP-1, and ASK) are sensitive to reactive oxygen species. Insulin binding to insulin receptor induces the activation of NADP(H) oxidase by some pathways not completely identified, but P22phox, Rac, and Gai2 are potential candidates for this signal transduction from insulin receptor to $\mathrm{NADP}(\mathrm{H})$ oxidase. The $\mathrm{H}_{2} \mathrm{O}_{2}$ produced inactivates the proteins sensitive to oxidation (gray squares), which allows insulin signaling. The production of reactive oxygen species by reversible oxidation and inhibition of phosphatases allows insulin signaling. Reactive oxygen species half-lives are short and are transiently produced. However, a higher production of reactive oxygen species from the endoplasmic reticulum or mitochondria after excessive lipid oxidation secondary to overfeeding could lead to the inhibition of antioxidant defense production caused by the inhibition of FOXO1 by JNK1. Moreover, the activation of JNK leads to the inhibition of IRS1. Whether reactive oxygen species promote or inhibit insulin signaling depends on the level and duration of exposure of the inner and outer cellular environment to reactive oxygen species. ASK, apoptosis signal-regulating kinase; FOXO1, Forkhead box 01; G $\alpha$ i2, G protein- $\alpha 2$; Gpx, glutathione peroxidase; Grb2, growth factor receptor-bound protein-2; GSK3, glycogen synthase kinase-3; $\mathrm{H}_{2} \mathrm{O}_{2}$, hydrogen peroxide; IR, insulin receptor; IRS, insulin receptor substrate; JNK1, cJun NH mitogen-activated protein kinase; MKP-1, tyrosine/serine mitogen-activated protein kinase phosphatase-1; NADP $(\mathrm{H})$, reduced nicotinamide adenine dinucleotide phosphate; $\mathrm{O}_{2}^{-}$, superoxide anion; P22phox, flavo-cytochrome b558 subunit; PI3K, phosphoinositide 3-kinase; PKC, protein kinase C; PP2A, serine protein phosphatase-2A; PTEN, phosphatase and tensin homolog; PTP1B, PTP, protein tyrosine phosphatase-1B; PTPases, protein tyrosine phosphatases; SOD, superoxide dismutase.

is much less evident or even absent for an unsaturated fat such as oleic acid. This has been confirmed by very recent work such as that by Michel et al. [14] on the involvement of small nucleolar RNAs in palmitate-induced oxidative stress and endoplasmic reticulum stress response with no effect of oleate, and the findings of Yuzefovych et al. [15] showing that palmitate but not oleate causes a significant increase in mitochondrial ROS production, which correlates with concomitant mitochondrial DNA damage, mitochondrial dysfunction, the induction of c-jun $\mathrm{N}$-terminal kinase, apoptosis, and an inhibition of insulin signaling. Clinical studies on the subject remain sparse and the results remain controversial. Perez-Martinez et al. [16] showed that, after a diet rich in monounsaturated fatty acids, postprandial lipid peroxidation levels, protein carbonyl concentrations, superoxide dismutase activity, and plasma hydrogen peroxide levels were lower compared with subjects adhering to a diet rich in saturated fatty acids. In contrast, in the LIPGENE study (a European multicentre dietary intervention study that investigates the effects of fat quality and quantity on risk factors associated with the metabolic syndrome), Petersson et al. [17] found no effect of dietary fat modification on oxidative stress and inflammatory markers. It has been established in several animal models that caloric restriction is one of the most effective ways to prolong life expectancy. The hypothesis regularly put forward for this effect is that it primarily involves a decrease of oxidative stress.

High-fat feeding and chronic fatty acid exposure also have been associated with increased ROS production in $\beta$-cells, leading to their dysfunction and cell death [18], and in hepatocytes, leading to hepatic IR [19]. Thus, the oxidative stress ignited by overnutrition can be found at all levels of the pathophysiologic mechanisms of T2D (Fig. 2).

\section{Dietary antioxidants and glucose metabolism}

Excessive energy intake in the form of saturated fatty acids and high glycemic index foods can be a source of oxidative stress. Conversely, plant-derived foods contain hundreds of active antioxidant compounds, including ascorbic acid, tocopherols, carotenoids, and a wide range of phytochemicals such as phenolic acids and flavonoids. They modulate oxidative stress and protect against oxidative damage and its complications such as IR.

Many in vitro and animal studies have shown that a large range of dietary antioxidants, taken as extracts or as part of the food, have beneficial effects on glucose metabolism, including the prevention of T2D. Among them, polyphenols are the most studied and have shown very interesting results. To name only the most recent studies, quercetin, one of the most common flavonoids in the human diet, has demonstrated favorable effects on glucose metabolism by attenuating tumor necrosis factor- $\alpha$-mediated inflammation and IR in primary human adipocytes [20]; cyanidin$3-0-\beta$-glucoside, a thoroughly investigated anthocyanin, has demonstrated insulin-like activities by peroxisome proliferatoractivated receptor $\gamma$ activation in human omental adipocytes [21]; the citrus flavonoids hesperetin and naringenin have demonstrated a direct inhibition of tumor necrosis factor- $\alpha$-stimulated free fatty acid secretion in cultured mouse adipocytes [22], increased glucose uptake by AMP-activated protein kinase (AMPK) in cultured skeletal muscle cells [23], and improved insulin 


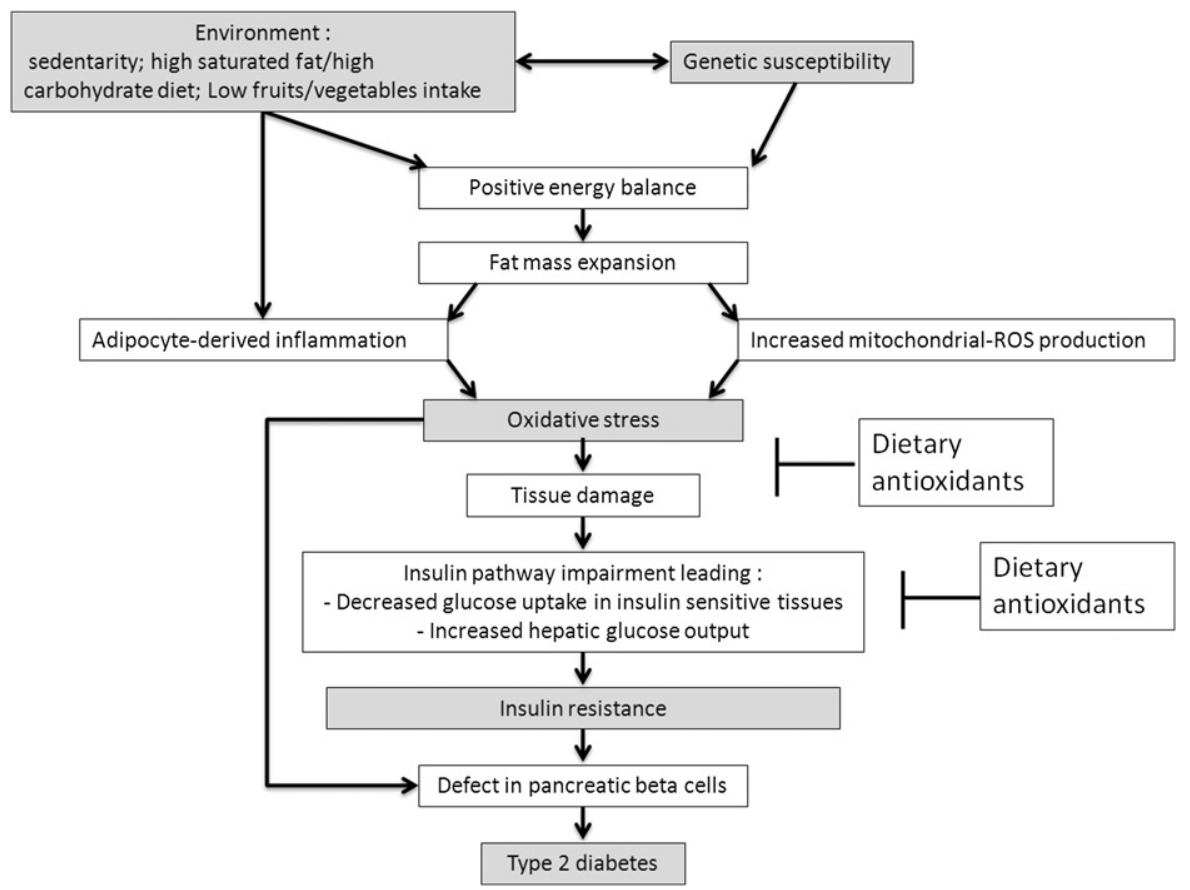

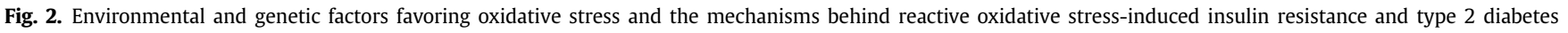
mellitus. ROS, reactive oxygen species.

sensitivity by increasing tyrosine phosphorylation in fructose-fed rats [24]. Also, luteolin, a flavonoid, has been shown to increase insulin sensitivity by an activation of peroxisome proliferatoractivated receptor- $\gamma$ transcriptional activity in 3T3-L1 adipocytes [25] and caffeic acid phenethyl ester potently has been found to stimulate glucose uptake in cultured skeletal muscle cells through the AMPK pathway [26] and stimulate glucose uptake in insulinresistant mouse hepatocytes, as has cinnamic acid [27]. One of the phenolic compounds whose effects have been largely studied on carbohydrate metabolism is unquestionably resveratrol, a phenolic compound of the stilbene family that, although exerting antioxidant properties, can interact directly with numerous metabolic pathways [28]. The studies by Lagouge et al. [29] and Baur et al. [30] showing how resveratrol improves energy balance, increases mitochondrial activity, and protects mice against dietinduced obesity and IR constitute important defending arguments on how this compound may play an important role in the prevention of metabolic diseases and diabetes. Its different actions on glucose metabolism are not restricted to its antioxidant capacity but rather are mediated through sirtuin 1 and thus associated with gene sequence silencing [20,31-34].

We therefore understand that experimental data are abundantly in favor of the central role of oxidative stress in IR, on the one hand, and of the protective effect of dietary antioxidants against these metabolic alterations, on the other hand. However, intervention studies directly assessing the effects of antioxidants on glucose metabolism in humans are rare and very few have used the insulin clamp technique, the gold standard method in assessing insulin sensitivity. The effects of $\alpha$-lipoic acid and vitamin $C$ and $E$ supplementation alone or in association with other antioxidants have been evaluated using this method and have shown positive effects [3]. These positive results must be weighed against other studies with less favorable conclusions such as the recently published study by Yfanti et al. [35] indicating that the administration of antioxidants in the combined form of vitamin C (500 mg/d) and vitamin E (400 IU/d) during strenuous endurance training had no effect on the traininginduced increase in insulin sensitivity. These data complement those of Ristow et al. [36] showing that supplementation with a combination of these same vitamins at high doses $(1000 \mathrm{mg} /$ $\mathrm{d}$ and $400 \mathrm{IU} / \mathrm{d}$, respectively) may preclude the healthpromoting effect of exercise on improved insulin sensitivity. However, these data are in conflict with the finding suggesting that high levels of vitamin $C$ do not decrease the positive effects of exercise [37] and even decrease the risk of T2D [38]. Regarding polyphenols only, few studies have evaluated their effects on insulin sensitivity using the insulin clamp. In fact, only one study showed that cocoa consumption for 2 wk had no effect on the insulin sensitivity of hypertensive patients [39]. Very recently, the metabolic effects of resveratrol identified thus far in animals were confirmed in a clinical trial [40]. In this work, the investigators reported that a substantially high dose of 150 $\mathrm{mg} / \mathrm{d}$ of trans-resveratrol (average daily intake in Europe of about $0.01-0.45 \mathrm{mg} / \mathrm{d}$ [41]) taken for $1 \mathrm{mo}$ had favorable effects on glucose homeostasis in obese subjects by improving their homeostasis model assessment index, thus indicating favorable effects on insulin sensitivity. Unfortunately, the investigators could not determine if these effects resulted in an amelioration of whole-body insulin sensitivity when using the insulin clamp.

Epidemiologic studies have reported experimental data of diets rich in antioxidants such as vitamin C [38], vitamin E [42], $\alpha$-tocopherol [43], or $\beta$-carotene [43] exhibiting beneficial effects on glucose metabolism and on diabetes prevention. Two metaanalyses examined the association between the intake of fruit, vegetables, and antioxidants and the risk of T2D. The major finding of the first study is that the consumption of antioxidants but not of fruits and vegetables was associated with a $13 \%$ decrease in the risk of T2D, mainly attributed to vitamin E [44], whereas in the second, the intake of green leafy vegetables was associated with a $14 \%$ decrease of the same risk [45].

The problem is that when reviewing clinical intervention trials evaluating the effects of antioxidant supplementation, it is hard to 
Table 2

Main antioxidants, their natural sources, and recent evidence concerning their effects on glucose metabolism in humans

\begin{tabular}{|c|c|c|}
\hline Antioxidant compounds & Type of study & Effects on glucose metabolism \\
\hline \multicolumn{3}{|l|}{ Polyphenols } \\
\hline $\begin{array}{l}\text { Flavonols: quercetin, myricetin, kampeferol (peas, } \\
\text { carrot, broccoli, spinach, cauliflower, apple, plum, } \\
\text { apricot, strawberries, tomatoes, black and green teas) }\end{array}$ & prospective epidemiological study & $\begin{array}{l}\text { high intake of flavonols and flavones not associated with } \\
\text { decrease in T2D, although a modest inverse association with } \\
\text { apples and tea intake cannot be ruled out [49]; no effect }\end{array}$ \\
\hline $\begin{array}{l}\text { Flavanols: catechins, epicatechin (cocoa, black } \\
\text { chocolate, black and green teas) }\end{array}$ & randomized controlled trial & epicatechin has no effect on IR [50]; no effect \\
\hline $\begin{array}{l}\text { Anthocyanins: cyanidin, delphinidin, luteolinidin } \\
\text { (berries, orange, eggplant, cherries, red grape, red } \\
\text { wine) }\end{array}$ & randomized trial & $\begin{array}{l}\text { flaxseed supplementation decreases thiobarbituric acid- } \\
\text { reactive substances, plasma glucose, and HOMA-IR of } \\
\text { overweight, hypertensive subjects with family history of } \\
\text { diabetes [51]; positive effect }\end{array}$ \\
\hline $\begin{array}{l}\text { Isoflavones: genistin, formononetin, coumestrol (Soy, } \\
\text { black beans, alfalfa, peanuts) }\end{array}$ & randomized controlled trial & $\begin{array}{l}\text { supplement containing combination of antioxidants } \\
\text { extracted from fruit, berries, and vegetables has no effect on } \\
\text { blood glucose, HbA1c, insulin [52]; no effect }\end{array}$ \\
\hline \multicolumn{3}{|l|}{$\begin{array}{l}\text { Flavanones: hesperidin, naringenin (orange, grapefruit, } \\
\text { lemon, lime, tomato skin) }\end{array}$} \\
\hline \multicolumn{3}{|l|}{$\begin{array}{l}\text { Flavones: apigenin, luteolin, tangeritin (parsley, celery, } \\
\text { sweet pepper) }\end{array}$} \\
\hline \multirow[t]{3}{*}{$\begin{array}{l}\text { Hydroxycinnamic acid derivatives: chlorogenic acid, } \\
\text { caffeic acid, hydrocinnamic acid (blueberries, coffee, } \\
\text { kiwi fruit, apples, pears, red wine, broccoli, plums, } \\
\text { cherries) }\end{array}$} & epidemiologic, cross-sectional study & $\begin{array}{l}\text { coffee but not green tea consumption has beneficial effects } \\
\text { on glycemic parameters (fasting plasma glucose, HOMA-IR, } \\
\text { HOMA- } \beta \text {, plasma HbA1c) in multiethnic Asian population } \\
\text { [54]; positive effect of coffee, no effect of tea }\end{array}$ \\
\hline & prospective epidemiologic study & $\begin{array}{l}\text { long-term consumption of oolong tea may be predictive } \\
\text { factor for new-onset diabetes in a Japanese population [55]; } \\
\text { negative effect }\end{array}$ \\
\hline & $\begin{array}{l}\text { randomized controlled trial } \\
\text { meta-analysis of cohort studies }\end{array}$ & $\begin{array}{l}\text { green tea extract has no effect on IR [56]; no effect } \\
\text { consumption of } \geq 4 \text { cups/d of tea has beneficial effect on T2D } \\
\text { prevention [57]; positive effect }\end{array}$ \\
\hline \multicolumn{3}{|l|}{ Stilbenoids } \\
\hline \multirow[t]{2}{*}{$\begin{array}{l}\text { Trans-resveratrol (skin of red grapes, cranberries, } \\
\text { blueberries, bilberries) }\end{array}$} & randomized controlled trial & $\begin{array}{l}\text { resveratrol supplementation improves HOMA-IR in patients } \\
\text { with T2D [34]; positive effect }\end{array}$ \\
\hline & randomized controlled trial & $\begin{array}{l}30 \mathrm{~d} \text { of high-dose resveratrol supplementation induces } \\
\text { favorable metabolic changes in obese humans, including } \\
\text { improvement in HOMA-IR [40]; positive effect }\end{array}$ \\
\hline $\begin{array}{l}\text { Carotenoids: } \beta \text {-cryptoxanthin, } \beta \text {-carotene, lutein (alfalfa, } \\
\text { carrot, tomato, grapefruit, watermelon) }\end{array}$ & randomized controlled trial & $\begin{array}{l}\text { no significant overall effects of vitamin C, vitamin E, and } \\
\beta \text {-carotene long-term supplementation (10 y) on risk of } \\
\text { developing T2D in women at high risk of CVD [47]; no effect }\end{array}$ \\
\hline
\end{tabular}

CVD, cardiovascular disease; Hb, hemoglobin; HOMA-IR, homeostasis model assessment for insulin resistance; IR, insulin resistance; T2D, type 2 diabetes mellitus

pinpoint the positive effects, with all the larger intervention trials that evaluated the diabetes-preventive potential of antioxidant supplements consisting of antioxidant vitamins with or without trace elements reporting negative outcomes [46,47]. Moreover, one study has suggested an increased risk of diabetes in the group supplemented with $\alpha$-tocopherol and/or $\beta$-carotene [48].

Thus, although experimental data on cellular and animal models seem quite clear on the role of oxidative stress in IR and on the positive effects of dietary antioxidants, human data show discrepancies. These discrepancies are found when comparing experimental data with human data, but also within human data. In this regard, it is interesting to note the results of tea consumption studies in humans. Several epidemiologic studies have shown how tea ingestion may be associated with an increased risk of diabetes. Conversely, other studies found no such effect, to the point where a meta-analysis suggested a protective effect of tea (Table 2) [34,40,47,49-59]. Several reasons can be given for these disparities. First, free radicals are necessary for the transduction of certain signals, including that of insulin, making their excessive neutralization deleterious. Second, the antioxidant capacity of dietary antioxidants may be modified by environmental conditions such as $\mathrm{pH}$, the presence of metal ions, or their concentration. In fact, antioxidants can become pro-oxidants beyond certain concentrations [60]. Third, digestion metabolism leading to the production of specific potent metabolites and conjugated derivatives and the complexity of food matrix synergism may explain some of the differences found between in vivo and in vitro studies. Fourth, the efficiency of most natural products and/or diet supplements possessing antioxidant-like actions is not restricted to their antioxidative capacity, which can further add to the variability in response, depending on the model studied. 


\section{Conclusions}

The involvement of ROS in the control of carbohydrate metabolism seems undeniable. Experimentally, the modulation of oxidative stress by antioxidants appears to have a positive outcome, but current intervention studies do not allow the recommendation of antioxidant supplementation for the sole purpose of preventing T2D. Most studies, however, have used supplements in the form of one or two vitamins associated or not with trace elements, although plants naturally contain a multitude of antioxidants. Among the countless compounds present in a particular plant food, it is often difficult to identify the one that plays the critical part; also, the overall total antioxidant capacity of the diet might be more important than the presence of any particular food [2]. Hence, the ideal antioxidant supplement for diabetes prevention will certainly be one that will be able to reproduce as closely as possible the innate combination of antioxidants found in plant foods even if we cannot exclude the fact that the beneficial effects of the latter might be synergistic with other compounds.

\section{References}

[1] Bulló M, Lamuela-Raventós R, Salas-Salvadó J. Mediterranean diet and oxidation: nuts and olive oil as important sources of fat and antioxidants. Curr Top Med Chem 2011;11:1797-810.

[2] Puchau B, Zulet MA, de Echávarri AG, Hermsdorff HHM, Martínez JA. Dietary total antioxidant capacity is negatively associated with some metabolic syndrome features in healthy young adults. Nutrition 2010;26:534-41.

[3] Bisbal C, Lambert K, Avignon A. Antioxidants and glucose metabolism disorders. Curr Opin Clin Nutr Metab Care 2010;13:439-46.

[4] Jones DP, Go Y-M. Redox compartmentalization and cellular stress. Diabetes Obes Metab 2010;12(suppl 2):116-25.

[5] Samocha-Bonet D, Heilbronn LK, Lichtenberg D, Campbell LV. Does skeletal muscle oxidative stress initiate insulin resistance in genetically predisposed individuals? Trends Endocrinol Metab 2010;21:83-8.

[6] Hoehn KL, Salmon AB, Hohnen-Behrens C, Turner N, Hoy AJ, Maghzal GJ, et al. Insulin resistance is a cellular antioxidant defense mechanism. Proc Natl Acad Sci U S A 2009;106:17787-92.

[7] Bonnard C, Durand A, Peyrol S, Chanseaume E, Chauvin M-A, Morio B, et al. Mitochondrial dysfunction results from oxidative stress in the skeletal muscle of diet-induced insulin-resistant mice. J Clin Invest 2008;118:789-800.

[8] Dandona P, Ghanim H, Chaudhuri A, Dhindsa S, Kim SS. Macronutrient intake induces oxidative and inflammatory stress: potential relevance to atherosclerosis and insulin resistance. Exp Mol Med 2010;42:245-53.

[9] Anderson EJ, Lustig ME, Boyle KE, Woodlief TL, Kane DA, Lin C-T, et al. Mitochondrial $\mathrm{H} 2 \mathrm{O} 2$ emission and cellular redox state link excess fat intake to insulin resistance in both rodents and humans. J Clin Invest 2009; 119:573-81.

[10] Sies H, Stahl W, Sevanian A. Nutritional, dietary and postprandial oxidative stress. J Nutr 2005;135:969-72.

[11] Bunck MC, Cornér A, Eliasson B, Heine RJ, Shaginian RM, Wu Y, et al. Oneyear treatment with exenatide vs. insulin glargine: effects on postprandial glycemia, lipid profiles, and oxidative stress. Atherosclerosis 2010;212:223-9.

[12] Madec S, Corretti V, Santini E, Ferrannini E, Solini A. Effect of a fatty meal on inflammatory markers in healthy volunteers with a family history of type 2 diabetes. Br J Nutr 2011;106:364-8.

[13] Amini M, Esmaillzadeh A, Shafaeizadeh S, Behrooz J, Zare M. Relationship between major dietary patterns and metabolic syndrome among individuals with impaired glucose tolerance. Nutrition 2010;26:986-92.

[14] Michel CI, Holley CL, Scruggs BS, Sidhu R, Brookheart RT, Listenberger LL, et al. Small nucleolar RNAs U32a, U33, and U35a are critical mediators of metabolic stress. Cell Metab 2011;14:33-44.

[15] Yuzefovych L, Wilson G, Rachek L. Different effects of oleate vs. palmitate on mitochondrial function, apoptosis, and insulin signaling in L6 skeletal muscle cells: role of oxidative stress. Am J Physiol Endocrinol Metab 2010;299:E1096-105.

[16] Perez-Martinez P, Garcia-Quintana JM, Yubero-Serrano EM, TassetCuevas I, Tunez I, Garcia-Rios A, et al. Postprandial oxidative stress is modified by dietary fat: evidence from a human intervention study. Clin Sci 2010;119:251-61.

[17] Petersson H, Risérus U, McMonagle J, Gulseth HL, Tierney AC, Morange S, et al. Effects of dietary fat modification on oxidative stress and inflammatory markers in the LIPGENE study. Br J Nutr 2010;104:1357-62.
[18] Andrikopoulos S. Obesity and type 2 diabetes: slow down!-can metabolic deceleration protect the islet beta cell from excess nutrient-induced damage? Mol Cell Endocrinol 2010;316:140-6.

[19] Raffaella C, Francesca B, Italia F, Marina P, Giovanna L, Susanna I. Alterations in hepatic mitochondrial compartment in a model of obesity and insulin resistance. Obesity (Silver Spring) 2008;16:958-64.

[20] Chuang C-C, Martinez K, Xie G, Kennedy A, Bumrungpert A, Overman A et al. Quercetin is equally or more effective than resveratrol in attenuating tumor necrosis factor- $\alpha$-mediated inflammation and insulin resistance in primary human adipocytes. Am J Clin Nutr 2010;92: 1511-21.

[21] Scazzocchio B, Varì R, Filesi C, D’Archivio M, Santangelo C, Giovannini C, et al. Cyanidin-3-O- $\beta$-glucoside and protocatechuic acid exert insulin-like effects by upregulating PPAR $\gamma$ activity in human omental adipocytes. Diabetes 2011;60:2234-44.

[22] Yoshida H, Takamura N, Shuto T, Ogata K, Tokunaga J, Kawai K, et al. The citrus flavonoids hesperetin and naringenin block the lipolytic actions of TNF-alpha in mouse adipocytes. Biochem Biophys Res Commun 2010; 394:728-32.

[23] Zygmunt K, Faubert B, MacNeil J, Tsiani E. Naringenin, a citrus flavonoid, increases muscle cell glucose uptake via AMPK. Biochem Biophys Res Commun 2010;398:178-83.

[24] Kannappan S, Anuradha CV. Naringenin enhances insulin-stimulated tyrosine phosphorylation and improves the cellular actions of insulin in a dietary model of metabolic syndrome. Eur J Nutr 2010;49:101-9.

[25] Ding L, Jin D, Chen X. Luteolin enhances insulin sensitivity via activation of PPAR $\gamma$ transcriptional activity in adipocytes. J Nutr Biochem 2010; 21:941-7.

[26] Eid HM, Vallerand D, Muhammad A, Durst T, Haddad PS, Martineau LC. Structural constraints and the importance of lipophilicity for the mitochondrial uncoupling activity of naturally occurring caffeic acid esters with potential for the treatment of insulin resistance. Biochem Pharmacol 2010;79:444-54.

[27] Huang D-W, Shen S-C, Wu JS-B. Effects of caffeic acid and cinnamic acid on glucose uptake in insulin-resistant mouse hepatocytes. J Agric Food Chem 2009;57:7687-92.

[28] Szkudelski T, Szkudelska K. Anti-diabetic effects of resveratrol. Ann N Y Acad Sci 2011;1215:34-9.

[29] Lagouge M, Argmann C, Gerhart-Hines Z, Meziane H, Lerin C, Daussin F, et al. Resveratrol improves mitochondrial function and protects against metabolic disease by activating SIRT1 and PGC-1alpha. Cell 2006;127:1109-22.

[30] Baur JA, Pearson KJ, Price NL, Jamieson HA, Lerin C, Kalra A, et al. Resveratrol improves health and survival of mice on a high-calorie diet. Nature 2006;444:337-42.

[31] de Kreutzenberg SV, Ceolotto G, Papparella I, Bortoluzzi A, Semplicini A, Dalla Man C, et al. Downregulation of the longevity-associated protein sirtuin 1 in insulin resistance and metabolic syndrome: potential biochemical mechanisms. Diabetes 2010;59:1006-15.

[32] Mercader J, Palou A, Bonet ML. Resveratrol enhances fatty acid oxidation capacity and reduces resistin and retinol-binding protein 4 expression in white adipocytes. J Nutr Biochem 2011;22:828-34.

[33] Vigilanza P, Aquilano K, Baldelli S, Rotilio G, Ciriolo MR. Modulation of intracellular glutathione affects adipogenesis in 3T3-L1 cells. J Cell Physiol 2011;226:2016-24.

[34] Brasnyó P, Molnár GA, Mohás M, Markó L, Laczy B, Cseh J, et al. Resveratrol improves insulin sensitivity, reduces oxidative stress and activates the Akt pathway in type 2 diabetic patients. Br J Nutr 2011;106:383-9.

[35] Yfanti C, Nielsen AR, Åkerström T, Nielsen S, Rose AJ, Richter EA, et al. Effect of antioxidant supplementation on insulin sensitivity in response to endurance exercise training. Am J Physiol Endocrinol Metab 2011 300:E761-70.

[36] Ristow M, Zarse K, Oberbach A, Klöting N, Birringer M, Kiehntopf M, et al. Antioxidants prevent health-promoting effects of physical exercise in humans. Proc Natl Acad Sci U S A 2009;106:8665-70.

[37] Thamer C, Machicao F, Stefan N, Fritsche A, Häring H-U. High baseline vitamin $C$ levels do not prevent a positive outcome of a lifestyle intervention. Diabetes Care 2009;32:e112.

[38] Harding A-H, Wareham NJ, Bingham SA, Khaw K, Luben R, Welch A, et al. Plasma vitamin C level, fruit and vegetable consumption, and the risk of new-onset type 2 diabetes mellitus: the European prospective investigation of cancer-Norfolk Prospective Study. Arch Intern Med 2008; 168:1493-9.

[39] Muniyappa R, Hall G, Kolodziej TL, Karne RJ, Crandon SK, Quon MJ. Cocoa consumption for 2 wk enhances insulin-mediated vasodilatation without improving blood pressure or insulin resistance in essential hypertension. Am J Clin Nutr 2008;88:1685-96.

[40] Timmers S, Konings E, Bilet L, Houtkooper RH, van de Weijer T, Goossens GH, et al. Calorie restriction-like effects of 30 days of resveratrol supplementation on energy metabolism and metabolic profile in obese humans. Cell Metab 2011;14:612-22.

[41] Edwards JA, Beck M, Riegger C, Bausch J. Safety of resveratrol with examples for high purity, trans-resveratrol, resVida $>>$. Ann N Y Acad Sci 2011;1215:131-7. 
[42] Costacou T, Ma B, King IB, Mayer-Davis EJ. Plasma and dietary vitamin E in relation to insulin secretion and sensitivity. Diabetes Obes Metab 2008; 10:223-8.

[43] Arnlöv J, Zethelius B, Risérus U, Basu S, Berne C, Vessby B, et al. Serum and dietary beta-carotene and alpha-tocopherol and incidence of type 2 diabetes mellitus in a community-based study of Swedish men: report from the Uppsala Longitudinal Study of Adult Men (ULSAM) study. Diabetologia 2009;52:97-105.

[44] Carter P, Gray LJ, Troughton J, Khunti K, Davies MJ. Fruit and vegetable intake and incidence of type 2 diabetes mellitus: systematic review and meta-analysis. BMJ 2010;341:c4229.

[45] Hamer M, Chida Y. Intake of fruit, vegetables, and antioxidants and risk of type 2 diabetes: systematic review and meta-analysis. J Hypertens 2007;25:2361-9.

[46] Czernichow S, Vergnaud A-C, Galan P, Arnaud J, Favier A, Faure H, et al. Effects of long-term antioxidant supplementation and association of serum antioxidant concentrations with risk of metabolic syndrome in adults. Am J Clin Nutr 2009;90:329-35.

[47] Song Y, Cook NR, Albert CM, Van Denburgh M, Manson JE. Effects of vitamins $\mathrm{C}$ and $\mathrm{E}$ and beta-carotene on the risk of type 2 diabetes in women at high risk of cardiovascular disease: a randomized controlled trial. Am J Clin Nutr 2009;90:429-37.

[48] Kataja-Tuomola M, Sundell JR, Männistö S, Virtanen MJ, Kontto J, Albanes D, et al. Effect of alpha-tocopherol and beta-carotene supplementation on the incidence of type 2 diabetes. Diabetologia 2008;51:47-53.

[49] Song Y, Manson JE, Buring JE, Sesso HD, Liu S. Associations of dietary flavonoids with risk of type 2 diabetes, and markers of insulin resistance and systemic inflammation in women: a prospective study and crosssectional analysis. J Am Coll Nutr 2005;24:376-84

[50] Brown AL, Lane J, Coverly J, Stocks J, Jackson S, Stephen A, et al. Effects of dietary supplementation with the green tea polyphenol epigallocatechin3-gallate on insulin resistance and associated metabolic risk factors: randomized controlled trial. Br J Nutr 2009;101:886-94.
[51] Rhee Y, Brunt A. Flaxseed supplementation improved insulin resistance in obese glucose intolerant people: a randomized crossover design. Nutr J $2011 ; 10: 44$

[52] Rytter E, Vessby B, Asgård R, Ersson C, Moussavian S, Sjödin A, et al. Supplementation with a combination of antioxidants does not affect glycaemic control, oxidative stress or inflammation in type 2 diabetes subjects. Free Radic Res 2010;44:1445-53.

[53] Golozar A, Khademi H, Kamangar F, Poutschi H, Islami F, Abnet CC, et al. Diabetes mellitus and its correlates in an Iranian adult population. PLoS ONE 2011;6:e26725.

[54] Rebello SA, Chen CH, Naidoo N, Xu W, Lee J, Chia KS, et al. Coffee and tea consumption in relation to inflammation and basal glucose metabolism in a multi-ethnic Asian population: a cross-sectional study. Nutr J 2011; 10:61.

[55] Hayashino Y, Fukuhara S, Okamura T, Tanaka T, Ueshima H. High oolong tea consumption predicts future risk of diabetes among Japanese male workers: a prospective cohort study. Diabet Med 2011;28:805-10.

[56] Hsu C-H, Liao Y-L, Lin S-C, Tsai T-H, Huang C-J, Chou P. Does supplementation with green tea extract improve insulin resistance in obese type 2 diabetics? A randomized, double-blind, and placebo-controlled clinical trial. Altern Med Rev 2011;16:157-63.

[57] Jing Y, Han G, Hu Y, Bi Y, Li L, Zhu D. Tea consumption and risk of type 2 diabetes: a meta-analysis of cohort studies. J Gen Intern Med 2009;24:557-62.

[58] Beydoun MA, Shroff MR, Chen X, Beydoun HA, Wang Y, Zonderman AB. Serum antioxidant status is associated with metabolic syndrome among U.S. adults in recent national surveys. J Nutr 2011;141:903-13.

[59] de Oliveira AM, Rondó PHC, Luzia LA, D’Abronzo FH, Illison VK. The effects of lipoic acid and $\alpha$-tocopherol supplementation on the lipid profile and insulin sensitivity of patients with type 2 diabetes mellitus: a randomized, doubleblind, placebo-controlled trial. Diabetes Res Clin Pract 2011;92:253-60.

[60] Bouayed J, Bohn T. Exogenous antioxidants-double-edged swords in cellular redox state: health beneficial effects at physiologic doses versus deleterious effects at high doses. Oxidative Med Cell Longevity 2010;3:228-37. 